\title{
Androgen receptor in breast cancer: expression in estrogen receptor-positive tumors and in estrogen receptor-negative tumors with apocrine differentiation
}

\author{
Leo A Niemeier ${ }^{1}$, David J Dabbs ${ }^{1}$, Sushil Beriwal ${ }^{2}$, Joan M Striebel ${ }^{1}$ and Rohit Bhargava ${ }^{1}$ \\ ${ }^{1}$ Department of Pathology, Magee-Women's Hospital of University of Pittsburgh Medical Center, Pittsburgh, \\ PA, USA and ${ }^{2}$ Department of Radiation Oncology, Magee-Women's Hospital of University of Pittsburgh \\ Medical Center, Pittsburgh, PA, USA
}

\begin{abstract}
Androgens exert growth inhibitory effects on estrogen receptor and progesterone receptor-negative breast cancer cell lines that show androgen receptor expression. These laboratory findings may be translated into inexpensive alternative therapies for hormone receptor-negative invasive breast cancers. Our aim was to systematically evaluate androgen receptor expression by immunohistochemistry in invasive breast cancers. Androgen receptor (clone AR441, Dako) expression was analyzed on 189 well-characterized consecutive invasive breast carcinomas represented with threefold redundancy on tissue microarrays. Androgen receptor expression was semi-quantitated using a histochemical score-like method and a score $>10$ was considered positive. Of the 189 consecutive invasive breast cancers, $151(80 \%)$ were positive and $38(20 \%)$ were negative for androgen receptor. The majority $(95 \%)$ of estrogen receptor-positive tumors were also androgen receptor positive. Of the estrogen receptor-negative tumors, androgen receptor reactivity was seen in 3 of $30(10 \%)$ triple-negative cases and in $5 / 8(63 \%)$ estrogen receptor-negative/progesterone receptor-negative/HER2 + cases. Six of eight estrogen receptor-negative/androgen receptor-positive cases showed apocrine differentiation. Androgen receptor expression in estrogen receptor-positive cases was associated with smaller tumor size $(P=0.0001)$, lower Nottingham grade $(P=0.002)$ and less frequent tumor cell necrosis $(P=0.0001)$. Androgen receptor expression in estrogen receptor-negative tumors was associated with lower Nottingham grade $(P=0.005)$ and apocrine differentiation $(P=0.039)$. In conclusion, most estrogen receptor-positive breast tumors also express androgen receptor. Androgen receptor expression in estrogen receptor-negative/ progesterone receptor-negative/HER2 + tumors (which commonly show apocrine differentiation) and a subset of triple - negative apocrine tumors suggest that these tumors together comprises the 'molecular apocrine' group described previously. However, these findings should be further confirmed on larger series of triplenegative and estrogen negative/progesterone negative/HER2 + tumors. Androgen receptor-targeted therapy in estrogen/progesterone receptor-negative tumors may provide an inexpensive alternative to usual high-dose chemotherapy with or without trastuzumab.
\end{abstract}

Modern Pathology (2010) 23, 205-212; doi:10.1038/modpathol.2009.159; published online 6 November 2009

Keywords: androgen receptor; breast carcinoma; apocrine differentiation

Breast cancer represents a diverse group of tumors that vary in clinical behavior and response to therapy. Currently, invasive breast cancer is treated

Correspondence: Dr R Bhargava, MD, Department of Pathology, Magee-Women's Hospital of UPMC, 300 Halket Street, Pittsburgh, PA 15213, USA.

E-mail: rbhargava@mail.magee.edu

Received 13 April 2009; revised 16 June 2009; accepted 7 August 2009; published online 6 November 2009 by multi-modality therapy. Approximately $75 \%$ of breast cancers are positive for estrogen (ER) and/or progesterone (PR) receptor protein expression. This group of tumors is generally responsive to selective estrogen receptor modulators, ${ }^{1}$ with relative resistance seen in a subset of tumors co-expressing HER2. ${ }^{2}$ The remaining $20-25 \%$ of breast cancers are ER and PR negative and are not amenable to selective estrogen receptor modulators. This hormone receptor-negative group includes triple-nega- 
tive tumors (negative for ER, PR and HER2) and a subset of tumors, which are positive for HER-2/neu (ERBB2). The HER2-positive tumors are now often treated with humanized monoclonal antibody to HER2 protein called trastuzumab in adjuvant, neoadjuvant and metastatic settings. Although, the therapy with trastuzumab is effective, it is not without serious cardiotoxicity in some patients ${ }^{3,4}$ and is very expensive (approximately \$50 00060000 for 1 year). However, triple-negative breast cancers lack any specific targeted therapy at the current time. ${ }^{5}$ The search for more predictive biomarkers is the primary aim and goal of breast cancer research.

In an effort to identify additional predictive biomarkers, we studied androgen receptor (AR) expression in breast cancers. AR has biological and therapeutic utilization in prostate cancer, but its use in breast cancer treatment is limited because of the widespread and effective use of anti-estrogen hormonal therapies and dearth of studies comprehensively analyzing AR expression in breast cancer. ${ }^{6}$ Recent literature has shown that Dehydroepiandrosterone and its sulfate have growth inhibitory effects on ER- and PR-negative breast cancer cell lines that show AR expression. ${ }^{7-9}$ The aim of our study was to examine the prevalence of AR positivity in the various subclasses of invasive breast cancer. Of particular interest was the percentage of AR expression in the hormone receptor-negative group and if there were any recurring morphological features that were present in these tumors.

\section{Materials and methods}

AR expression was evaluated on 189 consecutive invasive breast carcinomas represented on tissue microarrays with threefold redundancy. Four tissue microarrays were constructed using $0.6 \mathrm{~mm}$ cores on manual microarrayer MTA1 from Beecher Instruments, Sun Prairie, WI, USA. Four micrometer microarray sections were immunostained with AR antibody on the Dako automated stainer (Dako North America, Carpinteria, CA, USA). The protocol consisted of a pretreatment in Trilogy with EDTA (Cell Marque, Rocklin, CA, USA), in a steamer $30 \mathrm{~min}$ at $95-99^{\circ} \mathrm{C}$ and then cooled at room temperature for $30 \mathrm{~min}$. Slides were then placed on the immunostainer and incubated with the AR antibody (clone AR441; dilution 1:50; Dako). The antigen-antibody complexes were detected by using mouse EnVision + (Dako). AR expression was semiquantitatively scored using an H-score like method described below. An immunohistochemical score $>10$ was considered as a positive result.

The tumor ER, PR, and HER2 status was available from pathology reports. Immunohistochemistry for ER and PR was performed using the $6 \mathrm{~F} 11$ and $1 \mathrm{~A} 6$ antibodies, respectively, and iVIEW detection on the BenchMark XT (Ventana, Tucson, AZ, USA) at the time of initial diagnosis. At our institution, ER and $\mathrm{PR}$ are scored using a semi-quantitative $\mathrm{H}$-score like method which details the percentage of cells showing none, weak, moderate or strong staining. ${ }^{10,11}$ The score is given as the sum of the percent staining multiplied by an ordinal value corresponding to the intensity level $(0=$ none, $1=$ weak, $2=$ moderate and $3=$ strong). With four intensity levels, the resulting score ranges from 0 (no staining in the tumor) to 300 (diffuse strong staining of the tumor). An immunohistochemical score $>10$ was considered a positive result for ER and PR. HER-2/ neu protein was analyzed and scored using CB11 antibody and basic DAB detection on BenchMark XT (Ventana, Tucson, AZ, USA). HER-2/neu slides were reviewed and scored as follows: 0 as no membranous reactivity or reactivity in $<10 \%$ of the tumor cells; $1+$ as faint/barely perceptible membranous reactivity in $>10 \%$ of the tumor cells; $2+$ as weak to moderate complete membranous staining in $>10 \%$ of the tumor cells; and $3+$ as strong membranous staining in $>30 \%$ of the tumor cells. HER-2/neu was considered as negative for immunohistochemical scores 0 and 1. HER-2/neu was considered as positive with either $3+$ immunoreactivity or unequivocal amplification by fluorescence in situ hybridization (PathVysion Vysis dual color FISH by Vysis, Downers Grove, IL, USA) in $2+$ cases. Cases with 'equivocal results' by fluorescence in situ hybridization were considered as negative for HER2 in this study.

Based on semiquantitative ER, PR and HER2 results, the tumors were divided in six groups corresponding to molecular classes as follows: Luminal A (LUMA; ER score of 200 or higher, any PR and HER2 negative), Luminal B (LUMB; ER score of 11-199 or PR $>10$ and HER2 negative), ERBB2 (ER and PR score of 10 or less and HER2 positive), Triple Negative (TN; ER and PR score of 10 or less and HER2 negative), Luminal A-HER2 Hybrid (LAHH; ER score 200 or higher, any PR and HER2 positive), Luminal B-HER2 Hybrid (LBHH; ER score of 11-199 or PR > 10 and HER2 positive). ${ }^{12}$ As the main distinction between luminal $\mathrm{A}$ and luminal B tumors on expression profiling was the quantitative expression levels of ER and ER-related genes, ${ }^{13}$ we have used semi-quantitative hormone receptor immunohistochemistry for this distinction. Therefore, our criteria slightly differ from previous studies that used immunohistochemistry as a surrogate for molecular classification. ${ }^{14-16}$ This approach is concordant with the molecular classification, and also helps distinguish between weak ER + tumors from strong ER + tumors because these tumors appear to respond differently to hormonal therapy. ${ }^{17-20}$ A few previous studies have also classified luminal $\mathrm{B}$ tumors as $\mathrm{ER}+/ \mathrm{HER} 2+{ }^{14,16}$ but we choose to categorize them separately. Although ER + /HER2 + tumors tend to cluster with luminal $B$ tumors on gene expression profiling, ER + /HER2 + tumors constitute only a minority of luminal B tumors. 
The majority $(\geq 70 \%)$ of luminal $\mathrm{B}$ tumors are negative for HER2. Therefore, pure luminal tumors (LUMA and LUMB) were classified as positive for hormone receptors and negative for HER2. We believe this distinction is necessary as HER2 + tumors are treated differently and need to be separated from pure luminal tumors, which should be further categorized as luminal A and luminal B tumors.

The tumor AR expression was compared with known clinical-pathologic factors including the above described molecular classes. Apocrine differentiation in the tumor cells was identified based on cytologic features such as abundant granular eosinophilic cytoplasm, cytoplasmic vacuolization/ clearing, round vesicular nuclei, often with prominent eosinophilic (occasionally basophilic) nucleoli. If any of the cytoplasmic and nuclear features were present in combination in $>10 \%$ of the tumor cells, the tumor was considered to show apocrine differentiation.

Statistical analysis was performed using SPSS software version 16.0. For comparison of means, independent sample $t$-tests were performed. Univariate analysis was performed using $\chi^{2}$ and Fisher's exact tests to compare the differences in percentages between groups. An ANOVA test was performed to compare mean AR immunohistochemical scores and percentage cellular reactivity among different molecular classes. A $P$-value $<0.05$ was considered as significant.

\section{Results}

Of the total 189 cases, 151 (80\%) were positive and $38(20 \%)$ were negative for AR. The majority of $\mathrm{ER}+$ tumors were also positive for AR (Table 1 and Figure 1). Only 8 of the $151 \mathrm{ER}+$ cases were negative for $A R(5 \%)$. Interestingly, five of these eight AR-negative cases were also negative for PR. Of these five ER + /PR-/AR- cases, four belonged to the luminal $B$ class and only one belonged to the luminal A class (Table 2). Details of semiquantitative AR immunohistochemical staining for both AR-positive (H-score >10) and AR-negative (H-score 10 or less) cases is provided in Table 3 . There was no significant difference with respect to mean AR H-scores ( $P$-value, 0.806) or mean percentage of cell positivity $(P$-value, 0.869) in $A R+$ tumors of different molecular classes. The majority of the positive cases showed nuclear AR reactivity in $>80 \%$ of the tumor cells. The cases classified as AR negative (H-score 10 or less) were generally completely negative and showed an average reactivity in $1 \%$ of the tumor cells with $\mathrm{H}$-scores generally ranging from 0-5 (Table 3 ).

A comparison of $\mathrm{AR}+/ \mathrm{ER}+$ tumors $(n=143)$ with AR-/ER + tumors $(n=8)$ is shown in Table 4. The results that were significantly associated with AR-negative tumors were of larger tumor size, higher
Table 1 AR expression with respect to ER expression

\begin{tabular}{lccr}
\hline & ER positive & ER negative & Total \\
\hline AR positive & 143 & 8 & 151 \\
AR negative & $8^{\text {a }}$ & 30 & 38 \\
Total & 151 & 38 & 189 \\
\hline
\end{tabular}

${ }^{\mathrm{a}}$ Four were luminal A and 4 were luminal B (see Table 2). Five of these eight cases were also negative for PR.

Nottingham grade, and more frequent tumor cell necrosis. Although not statistically significant, a trend for frequent lymph-node metastases was noted for AR-negative tumors.

Among the two ER-negative molecular classes, AR positivity was seen in 8 of $38(21 \%)$ cases (Table 2); $10 \%(3 / 30)$ from the triple-negative group and $63 \%$ (5/8) from the ERBB2 group. As apocrine differentiation is commonly seen in ERBB2 tumors, 4 of the $5 \mathrm{AR}+$ ERBB2 tumors showed apocrine differentiation (Figure 2). Of the three $\mathrm{AR}+\mathrm{TN}$ tumors, two showed apocrine differentiation (Figure 3). Of all the 30 triple-negative tumors, nine showed some degree of apocrine differentiation, but only two were positive for AR.

A comparison of $\mathrm{AR}+/ \mathrm{ER}-$ tumors with $\mathrm{AR}-/$ ER- tumors is shown in Table 5. The results that were significantly associated with AR-negative tumors were higher Nottingham grade, and less frequent apocrine differentiation. Although none of the $\mathrm{AR}+$ tumors showed lymph node metastasis, this finding was not statistically significant between $\mathrm{AR}+/ \mathrm{ER}-$ and $\mathrm{AR}-/ \mathrm{ER}$ - groups, probably because of the small sample size. The results also showed that ER-negative apocrine tumors are commonly AR + .

\section{Discussion}

Similar to ER and PR, AR is also a steroid hormone nuclear receptor, ${ }^{21}$ but unlike ER and PR, AR expression in breast cancer is not as widely studied. In limited studies over the last two decades, AR expression has been observed in $>70 \%$ cases of breast carcinoma. ${ }^{22-24}$ This figure is concordant with the AR expression in $80 \%$ of the cases in this study of 189 consecutive invasive breast cancers. Gonzalez et $a l^{22}$ showed AR reactivity in $74.8 \%$ of 111 breast carcinomas using the same antibody clone and dilution used in this study. In a series of 76 breast carcinomas, Isola ${ }^{23}$ identified AR expression in $79 \%$ cases. In a series of 100 snap-frozen breast cancer tissues, Kuenen-Boumeester identified AR expression in $76 \%$ cases. $^{24}$ One large study of 488 cases from Poland has shown a lower rate $(43.4 \%)$ of AR expression in breast carcinoma, but this study also reported much lower rates of ER (39.3\%) and PR (24.6\%) expression. ${ }^{25}$ This study also used the same AR antibody clone and dilution as the 

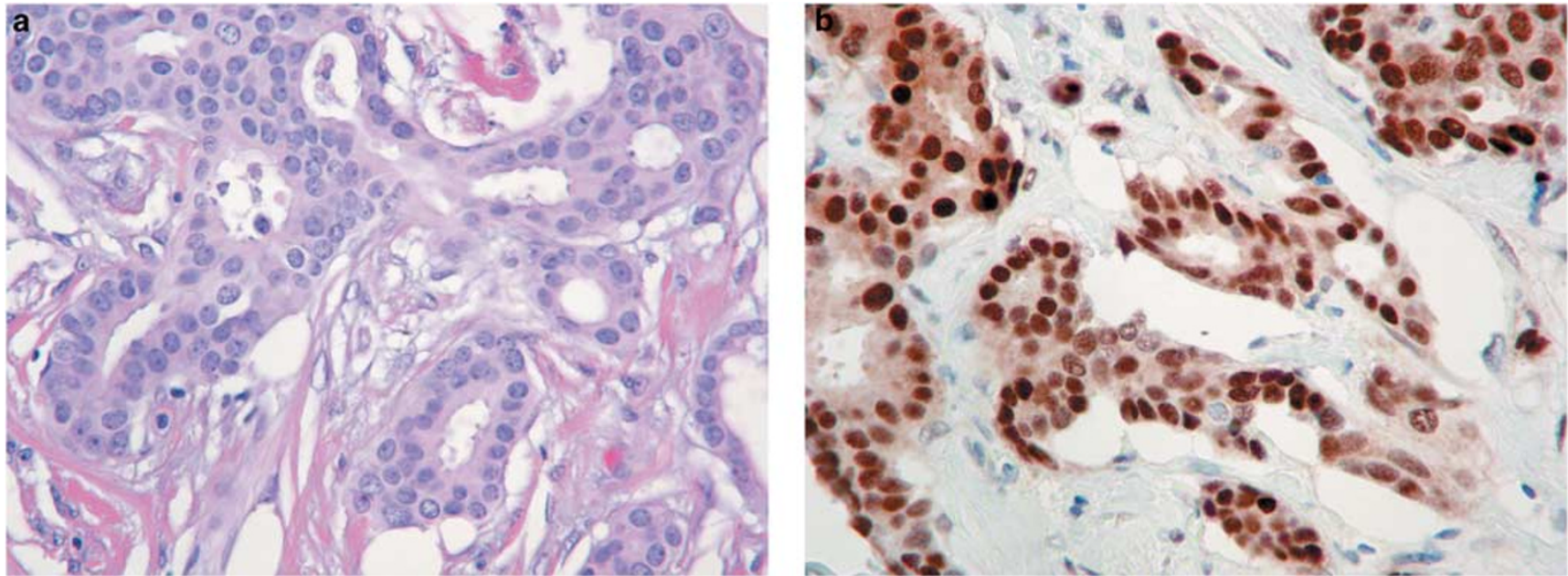

Figure 1 A prototypical Luminal A tumor $(\mathbf{a} ; \times 400, H \& E)$ showing strong AR reactivity $(\mathbf{b} ; \times 400$, anti-AR).

Table 2 AR expression in different molecular classes

\begin{tabular}{|c|c|c|c|c|}
\hline Molecular class & Criteria used & AR positive (\%) & AR negative (\%) & Total \\
\hline LUMA & Strong ER+, any PR, HER2 negative & $102(96)$ & $4(4)$ & 106 \\
\hline LUMB & Weak to moderate ER+ or PR+, HER2 negative & $24(86)$ & $4(14)$ & 28 \\
\hline ERBB2 & ER and PR negative, HER2+ & $5(63)$ & $3(37)$ & 8 \\
\hline $\mathrm{TN}$ & ER, PR, and HER2 negative & $3(10)$ & $27(90)$ & 30 \\
\hline LAHH & Strong ER+, any PR, HER2+ & $9(100)$ & $0(0)$ & 9 \\
\hline LBHH & Weak to moderate ER+ or PR+, HER2+ & $8(100)$ & $0(0)$ & 8 \\
\hline Total & & $151(80)$ & $38(20)$ & 189 \\
\hline
\end{tabular}

LAHH: luminal A-HER2 hybrid; LBHH: luminal B-HER2 hybrid; LUMA: luminal A; LUMB: luminal B; TN: triple negative.

Table 3 Semiquantitative immunohistochemical scoring details for AR expression in different molecular classes

\begin{tabular}{|c|c|c|c|c|}
\hline & H-score mean (median) & H-score range & $\begin{array}{l}\text { Percentage cells reactive } \\
\text { for AR-mean (median) }\end{array}$ & $\begin{array}{l}\text { Percentage cells reactive } \\
\quad \text { for AR-range }\end{array}$ \\
\hline LUMA: AR+ $(n=102)$ & $153(150)$ & $15-300$ & $87(100)$ & $15-100$ \\
\hline LUMB: $\mathrm{AR}+(n=24)$ & $150(145)$ & $20-300$ & $86(100)$ & $20-100$ \\
\hline ERBB2: $\mathrm{AR}+(n=5)$ & $178(170)$ & $60-280$ & $84(90)$ & $40-100$ \\
\hline $\mathrm{TN}: \mathrm{AR}+(n=3)$ & $185(260)$ & $25-270$ & $73(100)$ & $20-100$ \\
\hline LAHH: AR+ $(n=9)$ & $154(140)$ & $20-230$ & $91(100)$ & $20-100$ \\
\hline LBHH: $\mathrm{AR}+(n=8)$ & $124(100)$ & $80-220$ & $83(88)$ & $60-100$ \\
\hline LUMA: AR- $(n=4)$ & $6(5)$ & $5-10$ & $6(5)$ & $5-10$ \\
\hline LUMB: $\mathrm{AR}-(n=4)$ & $0(0)$ & $0-0$ & $0(0)$ & $0-0$ \\
\hline ERBB2: AR- $(n=3)$ & $2(0)$ & $0-5$ & $2(0)$ & $0-5$ \\
\hline $\mathrm{TN}: \mathrm{AR}-(n=27)$ & $1(0)$ & $0-5$ & $1(0)$ & $0-5$ \\
\hline LAHH: AR- $(n=0)$ & NA & NA & NA & NA \\
\hline LBHH: $\mathrm{AR}-(n=0)$ & NA & NA & NA & NA \\
\hline All AR+ cases $(n=151)$ & $152(150)$ & $15-300$ & $87(100)$ & $15-100$ \\
\hline All AR- cases $(n=38)$ & $1(0)$ & $0-10$ & $1(0)$ & $0-10$ \\
\hline
\end{tabular}

LAHH: luminal A-HER2 hybrid; LBHH: luminal B-HER2 hybrid; LUMA: luminal A; LUMB: luminal B; TN: triple negative; NA: not applicable.

current study and also used antigen retrieval. Whether this lower rate of steroid receptor expression was related to geographical distribution, tissue fixation or somewhat younger age of the patients (average age of 54 years) is unclear. Interestingly, criterion for positivity was not mentioned. Previous studies have also shown an association with ER expression ${ }^{23}$ and some reports indicated AR expression in ER-negative tumors. ${ }^{24,26}$

In the last few years our understanding of breast carcinoma has significantly improved with discovery of breast cancer molecular classes using the 
Table 4 Clinical-pathological features of AR+/ER+ and AR-negative/ER+ tumors

\begin{tabular}{lccc}
\hline & AR+/ER+ $(\mathrm{n}=143)$ & AR-/ER+ $(\mathrm{n}=8)$ & P-value \\
\hline Average age & 61 years & 59 years & 0.644 \\
Mean tumor size (median) & $1.6 \mathrm{~cm}(1.4 \mathrm{~cm})$ & $2.9 \mathrm{~cm}(2.5 \mathrm{~cm})$ & $0.0001^{*}$ \\
Ductal phenotype & $129 / 143(90 \%)$ & $5 / 8(88 \%)$ & 0.875 \\
Nottingham grade III & $20 / 143(14 \%)$ & $4 / 8(63 \%)$ & $0.002^{*}$ \\
Necrosis & $0 / 143(0 \%)$ & $1 / 8(50 \%)$ & $0.0001^{*}$ \\
Apocrine differentiation & $8 / 143(6 \%)$ & $5 / 7(71 \%) ; 1 \mathrm{NA}$ & 0.422 \\
Lymph node metastasis & $43 / 128(34 \%) ; 15 \mathrm{NA}$ & 0.09 \\
\hline
\end{tabular}

NA: Not available.

*Statistically significant.
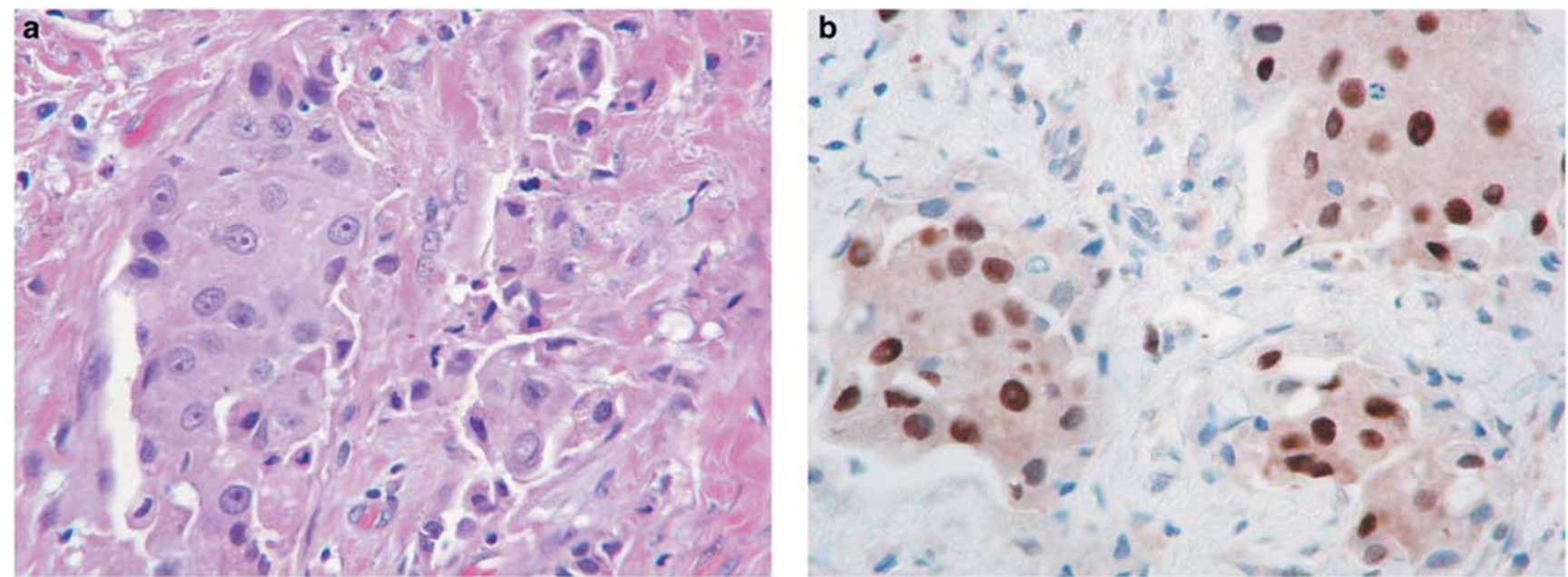

Figure 2 A triple negative (ER negative, PR negative and HER2 negative) apocrine tumor (a; $\times 400$, H\&E) showing strong AR reactivity (b; $\times 400$, anti-AR).
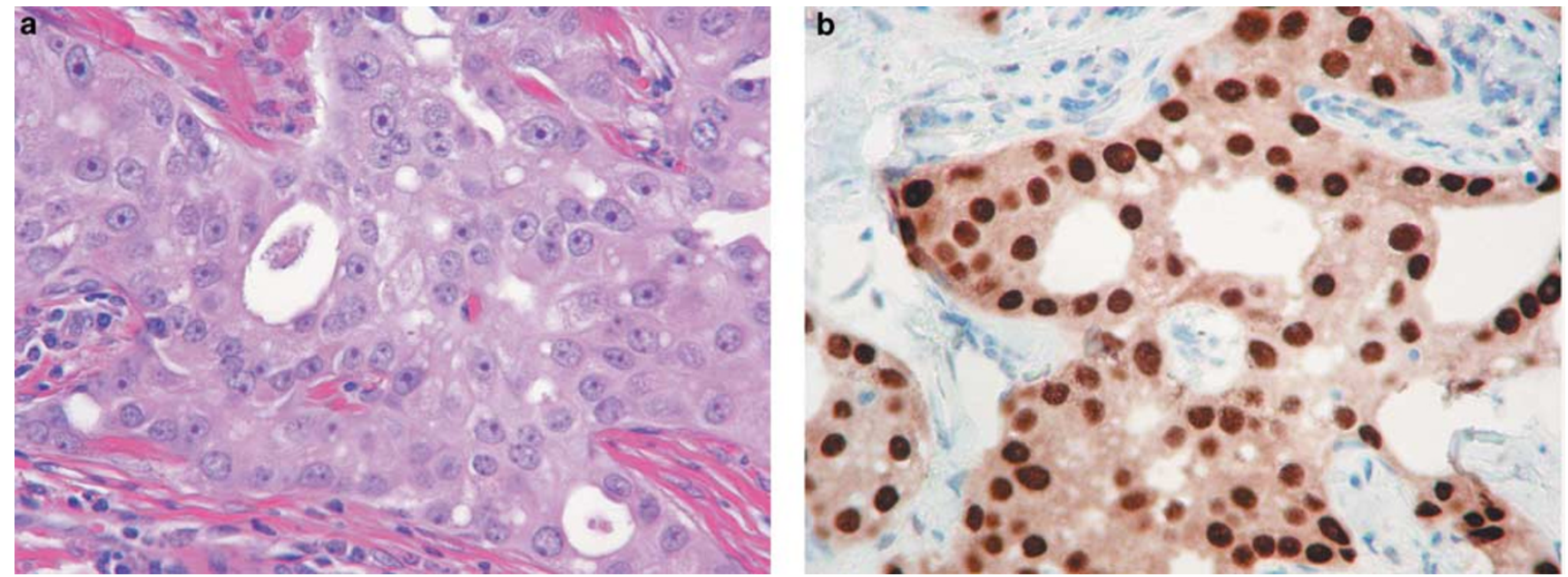

Figure 3 An ERBB2 tumor (ER negative, PR negative, and HER2 positive) with apocrine differentiation (a; $\times 400$, H\&E) showing strong reactivity for AR $(b ; \times 400$, anti-AR).

'intrinsic' gene set, that has prognostic significance. ${ }^{13,27,28}$ During the same time period, other gene expression-based tests have also proliferated, but the core significance of ER, PR and HER2 as prognostic/predictive markers has not diminished. It appears that broad division of breast cancer into
ER-positive and ER-negative groups has enormous biological and clinical significance. Therefore, ER, PR and HER2 have been used as immunohistochemical surrogate markers for molecular classes yielding comparable results. ${ }^{14,29}$ We designed this study to analyze AR expression in breast carcinoma 
Table 5 Clinical-pathological features of AR+/ER-negative and AR-negative/ER-negative tumors

\begin{tabular}{|c|c|c|c|}
\hline & $A R+/ E R-(\mathrm{n}=8)$ & $A R-/ E R-(\mathrm{n}=30)$ & $\mathrm{P}$-value \\
\hline Average age & 63 years & 57 years & 0.245 \\
\hline Mean tumor size (median) & $1.5 \mathrm{~cm}(1.4 \mathrm{~cm})$ & $2.2 \mathrm{~cm}(2.0 \mathrm{~cm})$ & 0.151 \\
\hline Ductal phenotype & $8 / 8(100 \%)$ & $30 / 30(100)$ & NS \\
\hline Nottingham grade III & $3 / 8(38 \%)$ & $27 / 30(90 \%)$ & $0.005^{*}$ \\
\hline Necrosis & $1 / 8(13 \%)$ & $10 / 30(33 \%)$ & 0.295 \\
\hline Apocrine differentiation & $6 / 8(75 \%)$ & $9 / 30(30 \%)$ & $0.039 *$ \\
\hline Lymph node metastasis & $0 / 7(0 \%) ; 1 \mathrm{NA}$ & $8 / 26(31 \%) ; 4$ NA & 0.154 \\
\hline
\end{tabular}

NA: Not available; NS: not significant.

* Statistically significant.

with respect to IHC-defined molecular classes and also its relationship to other clinical-pathological factors.

Our results indicate that almost all ER + tumors express AR; however, in the ER-negative group, AR expression is predominantly seen in ERBB2 molecular class. A few tumors in the triple-negative group can also express AR and the expression seems to be related to apocrine differentiation in these tumors. This observation has important biological and clinical significance. In 2005, Farmer et $a l^{30}$ studied 49 locally advanced breast cancers using Affymetrix U133A gene expression microarrays to define a 'molecular apocrine group'. This group was identified in addition to the previously described luminal and basal group. Their 'molecular apocrine tumors' showed more apocrine differentiation compared with other tumors, commonly showed ERBB2 gene amplification and AR signaling was most prominent in this group. Based on their findings, they suggested alternative breast cancer classification as $\mathrm{AR}+/ \mathrm{ER}+$ (luminal), AR-/ER- (basal), AR + /ER- (molecular apocrine). Our results parallel these findings in the fact that within our group of ERBB2 breast cancer, the majority of the tumors had apocrine differentiation (7/8) and five of these eight were also positive for AR. Another similar genomewide analysis of 99 breast cancers and eight breast cancer cell lines, showed a proliferative response to androgen in an AR-dependent and ER-independent manner in MDA-MB-453 cell line. ${ }^{31}$ Furthermore, the androgen-induced transcriptional program of MDA-MB-453 significantly overlapped the molecular signature of a unique ER-/PR- subclass of human tumors, which were also characterized by a hormonally regulated transcriptional program and response to androgen. This study provides morphologic and immunohistochemical validation to these gene expression findings. We speculate that 'molecular apocrine' tumors immunohistochemically are either ER-/PR-/HER2 +/AR + or ER-/PR-/ HER2-/AR + . Both tumor groups show histological evidence of apocrine differentiation in a large percentage of cases. We also suspect that the ERBB2 tumor class described using 'intrinsic' gene set is very similar, if not identical to the 'molecular apocrine class' described by Farmer et $a l^{30}$. How- ever, additional studies with larger number of ERBB2 tumors are required to confirm these findings. Recently, a concern has been raised that IHCbased categorization does not definitively identify the molecular classes defined by intrinsic gene set-based expression analysis. ${ }^{32}$ Specifically, it has been mentioned that ERBB2 tumor class consists of some tumors that are 'clinically HER2 negative'. A detailed examination of previous studies and the findings in this study suggests that some triplenegative tumors with apocrine differentiation and AR expression, cluster together with ERBB2 class and likely represent 'molecular apocrine' tumors.

Apart from these molecular studies described above, a few reports in the literature ties up the link(s) between apocrine differentiation, HER2 overexpression and AR expression. In an immunohistochemical study of 23 cases (10 cases of apocrine metaplasia, 3 apocrine ductal carcinoma in situ and 10 invasive apocrine carcinomas), Gatalica ${ }^{33}$ identified frequent AR expression, accompanied by loss of ER and PR in apocrine metaplasia and apocrine ductal carcinoma in situ, and to a certain extent in invasive apocrine carcinomas. No HER2 expression was analyzed in this study. Tavassoli et $a l^{34}$ identified AR expression in five of eight invasive apocrine carcinomas that were negative for ER and PR. Selim and Wells ${ }^{35}$ studied 82 cases of apocrine metaplasia (including 18 cases of apocrine adenosis), all of which were positive for AR but negative for ER and PR. We recently reviewed the morphology on 191 cases of invasive carcinoma treated with neo-adjuvant chemotherapy at our institution and found a strong statistically significant association between apocrine differentiation and ERBB2 (ie, ER-/PR-/HER2 + ) tumor type (paper under review). HER2 overexpression is also a common phenomenon in mammary Paget's disease and is because of the fact that in majority of instances Paget's disease is an extension of high-grade ductal carcinoma in situ often of the apocrine type. Liegl et $a{ }^{36}$ showed co-expression of HER2 and AR in $88 \%$ (51/58 cases) of Paget's disease. These subtle morpho-immunohistological associations seem to have a biological basis. Using breast cancer cell lines with 'molecular apocrine' features, Naderi et $a l^{37}$ showed a functional cross-talk between AR 
and HER2 pathways. This has immense therapeutic value as inhibition of the AR or HER2 pathways, alone or in combination, may result in additional therapies for ERBB2-type tumors.

As the majority of breast carcinomas show AR expression, the number of AR-negative tumors was rather limited in this study of consecutive invasive breast carcinomas. However, we still compared and contrasted AR-positive and AR-negative tumors, but did so separately for the ER-positive and ER-negative groups. In both ER-positive and ER-negative groups, AR expression was associated with more favorable clinical and pathological features. AR + tumors generally tend to be of smaller size, lower Nottingham grade, and less likely to have lymph-node metastasis. Although, these findings need to be explored in more detail with large number of cases; they still appear to be concordant with at least some previous studies, which suggested that AR expression is lost with more aggressive and larger tumors and AR expression in both ER-positive and ER-negative tumors is associated with improved recurrence free survival. ${ }^{38-41}$ The presence of AR expression in ER-negative tumors has a particular prognostic significance. Most ER-negative tumors (ie, ERBB2 and triplenegative tumors) are considered as aggressive, but it appears that AR reactivity can be used to prognosticate these tumors.

One important implication of this study is the use of AR-related targeted therapy for breast cancer, especially for ER-negative/AR-positive tumors. Preclinical studies have shown inhibitory roles of androgens like Dehydroepiandrosterone and its sulfate on ER-/PR-/AR + cells lines. Similar approaches can be used for ER-/AR + human breast cancers as an adjunctive therapy. As aromatase enzyme converts androgens into estrogens, it is thought that if androgens are used in the treatment of ER-/AR + tumors, the therapy should be combined with aromatase inhibitors for maximum benefit. $^{8,42}$ The use of AR-related targeted therapy for ER + breast cancer is somewhat more complicated. The use of androgens may actually stimulate the growth of ER + cells, ${ }^{43}$ as androgen response in $\mathrm{ER}+/ \mathrm{AR}+$ cells is different from ER-/AR + cells. If androgen-related targeted therapy has to be used for $\mathrm{ER}+/ \mathrm{AR}+$ tumors, it has to be directed towards inhibition of both AR and ER.

In summary, we have comprehensively examined AR expression in breast carcinomas, and conclude that AR expression parallels ER expression in majority of cases. AR expression in breast carcinomas appears to be a favorable prognostic factor. AR expression in ER-negative tumors can be exploited for an additional targeted therapy.

\section{Acknowledgement}

We thank Kim McManus for technical assistance.

\section{Disclosure/conflict of interest}

The authors declare no conflict of interest.

\section{References}

1 Sengupta S, Jordan VC. Selective estrogen modulators as an anticancer tool: mechanisms of efficiency and resistance. Adv Exp Med Biol 2008;630:206-219.

2 Prat A, Baselga J. The role of hormonal therapy in the management of hormonal-receptor-positive breast cancer with co-expression of HER2. Nat Clin Pract Oncol 2008;5:531-542.

3 Keefe DL. Trastuzumab-associated cardiotoxicity. Cancer 2002;95:1592-1600.

4 Piccart-Gebhart MJ, Procter M, Leyland-Jones B, et al. Trastuzumab after adjuvant chemotherapy in HER2positive breast cancer. N Engl J Med 2005;353: 1659-1672.

5 Tan AR, Swain SM. Therapeutic strategies for triplenegative breast cancer. Cancer J 2008;14:343-351.

6 Moe RE, Anderson BO. Androgens and androgen receptors: a clinically neglected sector in breast cancer biology. J Surg Oncol 2007;95:437-439.

7 Hardin C, Pommier R, Calhoun K, et al. A new hormonal therapy for estrogen receptor-negative breast cancer. World J Surg 2007;31:1041-1046.

8 Nahleh Z. Androgen receptor as a target for the treatment of hormone receptor-negative breast cancer: an unchartered territory. Future Oncol 2008;4:15-21.

9 Toth-Fejel S, Cheek J, Calhoun K, et al. Estrogen and androgen receptors as comediators of breast cancer cell proliferation: providing a new therapeutic tool. Arch Surg 2004;139:50-54.

10 Flanagan MB, Dabbs DJ, Brufsky AM, et al. Histopathologic variables predict Oncotype DX recurrence score. Mod Pathol 2008;21:1255-1261.

11 McCarty Jr KS, Miller LS, Cox EB, et al. Estrogen receptor analyses. Correlation of biochemical and immunohistochemical methods using monoclonal antireceptor antibodies. Arch Pathol Lab Med 1985;109:716-721.

12 Bhargava R, Striebel J, Beriwal S, et al. Prevalence, morphologic features and proliferation indices of breast carcinoma molecular classes using immunohistochemical surrogate markers. Int J Clin Exp Pathol 2009;2:444-455.

13 Sorlie T, Perou CM, Tibshirani R, et al. Gene expression patterns of breast carcinomas distinguish tumor subclasses with clinical implications. Proc Natl Acad Sci USA 2001;98:10869-10874.

14 Carey LA, Dees EC, Sawyer L, et al. The triple negative paradox: primary tumor chemosensitivity of breast cancer subtypes. Clin Cancer Res 2007;13:2329-2334.

15 Cheang MC, Voduc D, Bajdik C, et al. Basal-like breast cancer defined by five biomarkers has superior prognostic value than triple-negative phenotype. Clin Cancer Res 2008;14:1368-1376.

16 Tamimi RM, Baer HJ, Marotti J, et al. Comparison of molecular phenotypes of ductal carcinoma in situ and invasive breast cancer. Breast Cancer Res 2008;10:R67.

17 Allred DC, Harvey JM, Berardo M, et al. Prognostic and predictive factors in breast cancer by immunohistochemical analysis. Mod Pathol 1998;11:155-168.

18 Baehner FL, Watson D, Shak S, et al. Quantitative RT-PCR analysis of ER and PR by Oncotype DX 
indicates distinct and different associations with prognosis and prediction of tamoxifen benefit. 29th Annual San Antonio Breast Cancer Symposium 2006, Abstract \# 45.

19 Bhargava R, Chivukula M, Beriwal S, et al. Estrogen and Progesterone Receptors in Breast Carcinoma: Quantitation is Therapeutically Important. Adv Anat Pathol 2008;15:304-305.

20 Harvey JM, Clark GM, Osborne CK, et al. Estrogen receptor status by immunohistochemistry is superior to the ligand-binding assay for predicting response to adjuvant endocrine therapy in breast cancer. J Clin Oncol 1999;17:1474-1481.

21 Conzen SD. Minireview: nuclear receptors and breast cancer. Mol Endocrinol 2008;22:2215-2228.

22 Gonzalez LO, Corte MD, Vazquez J, et al. Androgen receptor expresion in breast cancer: relationship with clinicopathological characteristics of the tumors, prognosis, and expression of metalloproteases and their inhibitors. BMC Cancer 2008;8:149.

23 Isola JJ. Immunohistochemical demonstration of androgen receptor in breast cancer and its relationship to other prognostic factors. J Pathol 1993;170:31-35.

24 Kuenen-Boumeester V, Van der Kwast TH, van Putten $\mathrm{WL}$, et al. Immunohistochemical determination of androgen receptors in relation to oestrogen and progesterone receptors in female breast cancer. Int J Cancer 1992;52:581-584.

25 Agrawal AK, Jelen M, Grzebieniak Z, et al. Androgen receptors as a prognostic and predictive factor in breast cancer. Folia Histochem Cytobiol 2008;46:269-276.

26 Moinfar F, Okcu M, Tsybrovskyy O, et al. Androgen receptors frequently are expressed in breast carcinomas: potential relevance to new therapeutic strategies. Cancer 2003;98:703-711.

27 Perou CM, Sorlie T, Eisen MB, et al. Molecular portraits of human breast tumours. Nature 2000;406:747-752.

28 Sorlie T, Tibshirani R, Parker J, et al. Repeated observation of breast tumor subtypes in independent gene expression data sets. Proc Natl Acad Sci USA 2003;100:8418-8423.

29 Hugh J, Hanson J, Cheang MC, et al. Breast cancer subtypes and response to docetaxel in node-positive breast cancer: use of an immunohistochemical definition in the BCIRG 001 trial. J Clin Oncol 2009;27: 1168-1176.

30 Farmer P, Bonnefoi H, Becette V, et al. Identification of molecular apocrine breast tumours by microarray analysis. Oncogene 2005;24:4660-4671.

31 Doane AS, Danso M, Lal P, et al. An estrogen receptornegative breast cancer subset characterized by a hormonally regulated transcriptional program and response to androgen. Oncogene 2006;25: 3994-4008.

32 Parker JS, Mullins M, Cheang MC, et al. Supervised risk predictor of breast cancer based on intrinsic subtypes. J Clin Oncol 2009;27:1160-1167.

33 Gatalica Z. Immunohistochemical analysis of apocrine breast lesions. Consistent over-expression of androgen receptor accompanied by the loss of estrogen and progesterone receptors in apocrine metaplasia and apocrine carcinoma in situ. Pathol Res Pract 1997;193:753-758.

34 Tavassoli FA, Purcell CA, Bratthauer GL, et al. Androgen receptor expression along with loss of bcl-2, ER, and PR expression in benign and malignant apocrine lesions of the breast: implications for therapy. Breast J 1996;2:261-269.

35 Selim AG, Wells CA. Immunohistochemical localisation of androgen receptor in apocrine metaplasia and apocrine adenosis of the breast: relation to oestrogen and progesterone receptors. J Clin Pathol 1999;52:838-841.

36 Liegl B, Horn LC, Moinfar F. Androgen receptors are frequently expressed in mammary and extramammary Paget's disease. Mod Pathol 2005;18: 1283-1288.

37 Naderi A, Hughes-Davies L. A functionally significant cross-talk between androgen receptor and ErbB2 pathways in estrogen receptor negative breast cancer. Neoplasia 2008;10:542-548.

38 Agoff SN, Swanson PE, Linden H, et al. Androgen receptor expression in estrogen receptor-negative breast cancer. Immunohistochemical, clinical, and prognostic associations. Am J Clin Pathol 2003;120: $725-731$.

39 Gonzalez-Angulo AM, Stemke-Hale K, Palla SL, et al. Androgen receptor levels and association with PIK3CA mutations and prognosis in breast cancer. Clin Cancer Res 2009;15:2472-2478.

40 Honma N, Takubo K, Akiyama F, et al. Expression of GCDFP-15 and AR decreases in larger or node-positive apocrine carcinomas of the breast. Histopathology 2005;47:195-201.

41 Ogawa Y, Hai E, Matsumoto K, et al. Androgen receptor expression in breast cancer: relationship with clinicopathological factors and biomarkers. Int J Clin Oncol 2008;13:431-435.

42 Suzuki T, Miki Y, Akahira J, et al. Aromatase in human breast carcinoma as a key regulator of intratumoral sex steroid concentrations. Endocr J 2008;55:455-463.

43 Calhoun K, Pommier R, Cheek J, et al. The effect of high dehydroepiandrosterone sulfate levels on tamoxifen blockade and breast cancer progression. Am J Surg 2003;185:411-415. 